\title{
Inheritance Of Dark Head And Siphon In The Larvae Of Culex Quinqefasciatus Say
}

\author{
Badia a M. Al-chalabi and Ibrahim A. Ghaweel \\ Department of Environment - Public Health Faculty - Garyounis University, Libya
}

\begin{abstract}
A new spontaneous mutation (dh) is described for Culex quinquefasciatus Say. This phenotype was observed in the second generation to cause complete coloration of the head capsule and the siphon of the larvae. This character is mainly detectable in the larval stage and slightly in the adult stage .

The reciprocal mass matings between mutants from F2 generation and normal wild type sibs, revealed that the mode of inheritance can be controlled by an autosomal recessive gene (s) This happened for both sexes with slightly variability in their expression . No significant larval mortalities were found in all the crosses .
\end{abstract}

\section{Introduction}

Culex quinquefasciatus Say a species of pipiens complex is well known, medically important mosquito. It transmits virus diseases in several parts of the world, also it is involved in the epidemiology of Filariasis in many tropical area a swell as st. louis encephalitis .

Among mosquito species, Culex quinquefasciatus is one of the widely distributed one in the world . No records on diseases transmitted by this species has been reported for Libya so far .

Several investigators, Cheng (1972), Guptavanij and Barr (1979 and 1982) and Vandehey (1967) have studied relationship between the infection agent and the genetics of Culex mosquitoes to provide a basis of control for this species. In Culex pipiens complex.

Barr (1975) listed 47 mutants affecting larval, pupal and adult stages. Others; Dubash et al. (1982), Sharma et al. (1977) and Subbaraw and Adak (1978) have also found several mutants . Although a large number of mutations have been reported for this complex there is a striking lack of phenotypic markers for Culex quinquefasciatus which are essential in many genetic studies. Mutants affecting eye and body color extensively studied by Sakai et al. (1980), Shetty and Chowdaiah (1976) and Subbaraw and Adak (1978) . In
Iraq only two mutants of this species were found to affect larval growth ( Ouda et al. , 1986 and Ouda and Mehdi , 1988 ) .

The purpose of this study is to describe a new spontaneously isolated for this species and its mode of inheritance.

\section{Materials And Methods}

Several samples of mosquito larvae were collected and brought from small stagnant pond near Bennina airport / Benghazi City in October 2000 . The samples then reared in the laboratory. The dark head and siphon larvae were isolated from a second generation of an inbreed line. This is considered as a mutant of the larvae. The later caused complete coloration of the head capsule and the siphon. However, the scape of the antenna and an area around the eyes were pale in color. The head capsule of the mutant larva was rather spherical and wider than normal (Fig. 1).

This character is mainly detectable in the larval stage and slightly in the adult stage, moreover the mutant larvae were easy to distinguish from normal individuals . Although the larval instars of the mutants were all pigmented, separation of the mutant phenotype was not easily accomplished with first instar due to their size . 
In order to determine the mode of inheritance, reciprocal mass mating were made between mutants from F2 generation and normal wild type sibs . The egg rafts were isolated and reared as individual families in a half litre plastic dishes. The larvae were fed on rabbit chaw and reared in a glass door incubator at $28-1 \mathrm{C}^{\circ}$. The crosses were reported between individuals of three successive generation .

\section{Results And Discussion}

The breeding scheme (Fig. 2 ) shows the reciprocal crosses between mutant individuals and normal phenotypes. The later is the progeny of mass crosses of mutants for the wild types. The off springs of both crosses had dark head individuals , but had very little sex linkage to the (dh) gene or sex influenced expressions. This finding is incontrast to results obtained by Vandehey (1967), his results showed that similar phenotype in Culex pipiens is inherited as sex linked-gene .

In breeding of the progenies of normal phenotype individuals resulted from the crosses for the two generations produced similar ratios of wild to mutant phenotype in both F2 and F3 progenies (Fig. 3 ). The dark head that yielded from the above inbreeding had fewer individuals in F2 and
F3, and their percent were 1.9 and 5.2, respectively .

The inbreeding of dark line in two crosses produced few wild phenotype individuals in their F1 and F2 . This indicates that the expression of the character is slightly low .

When a reciprocal mass matings between the mutants of F2 generation and the normal wild type sibs, were made few dark head individuals resulted from their F3 progenies ( $13.9 \%$ and $4.3 \%$ ) in ( Fig. 4 ) .

The results presented in table (1) revealed that this phenotype is propably controlled by an autosomal recessive gene (s) with incomplete penetrance in both sexes and with slightly variable expression. The homozygous conditions of the mutant is variable in both sexes, but a phenotype of slow growing larvae was also observed in most families of all generation in various frequencies . Larval mortalities in most of the crosses were not significantly different . To determine the linkage group of the gene (s) and its mode of inheritance, further analysis should be made using large number of follow-up crosses as well as its interaction and / or linkage to other genes that already mapped for this species . Such mutations could be valuable tool for genetic control of this vector .

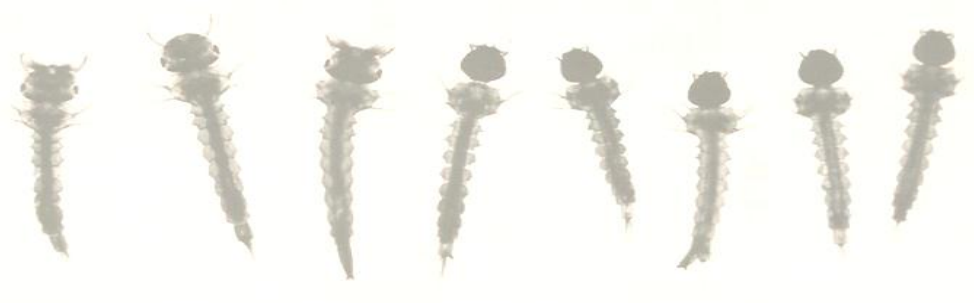

Fig. 1 : Mutant larvae of $C$. quinquefasciatus with dark, small and round head capsule ( 5 right) compared with normal larvae ( 3 left ). 
(a)

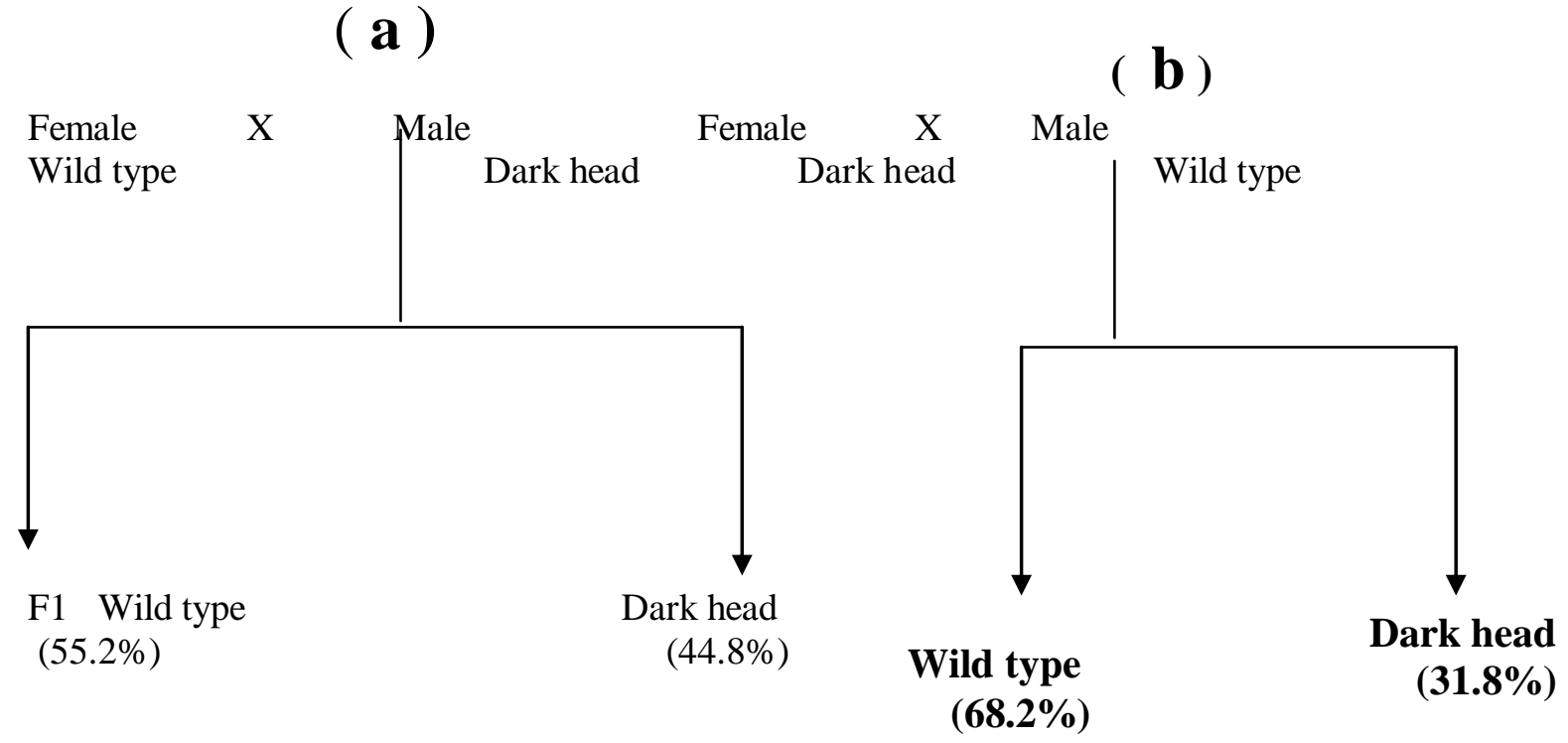

Fig. 2 : Breeding scheme showing comparison of the crosses between : (a) wild type female with dark head male, and (b) dark head female with wild type male .

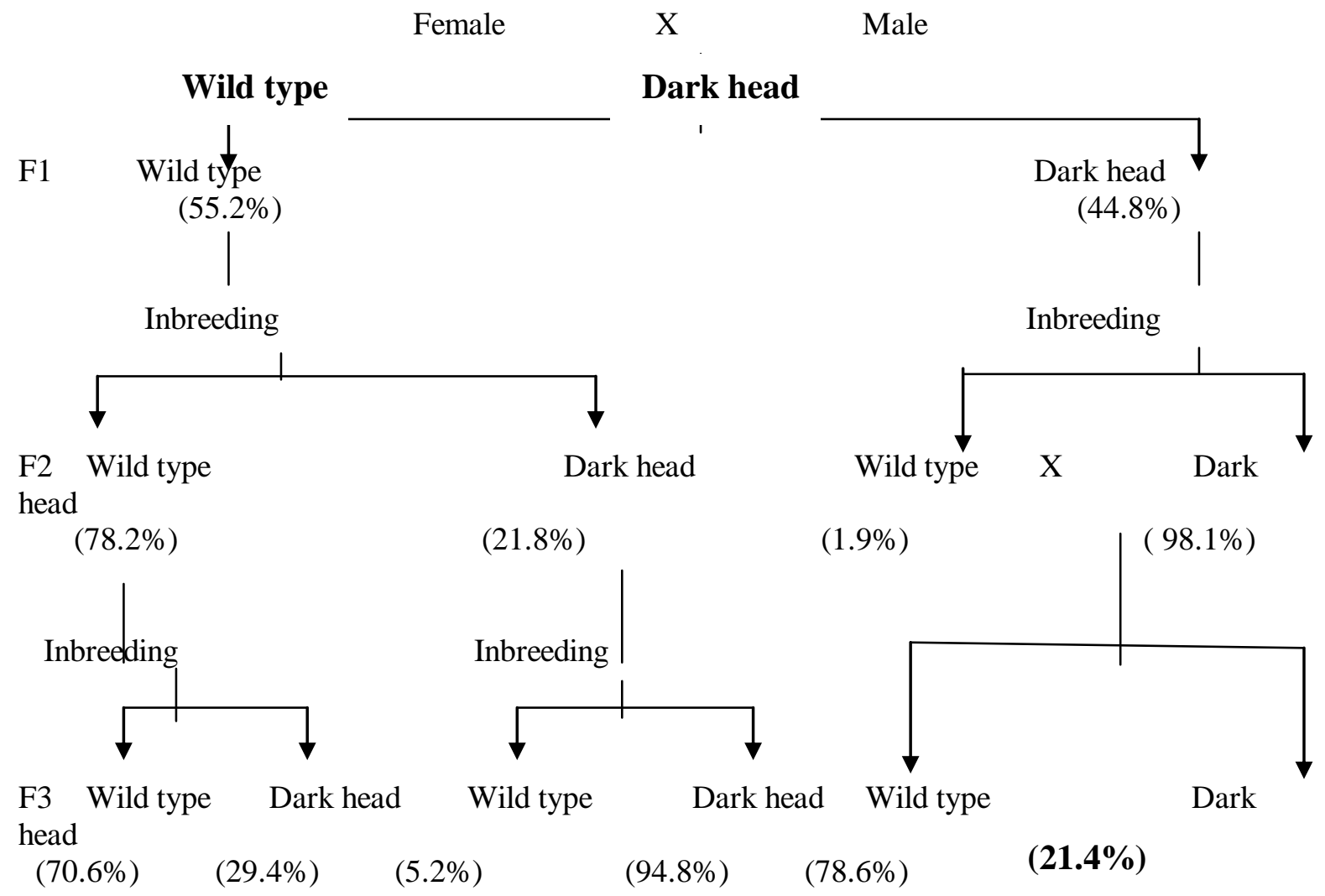

Fig. 3 : Breeding scheme showing crosses between wild type and dark head ( dh ) individuals with their offsprings for first and second generation . 


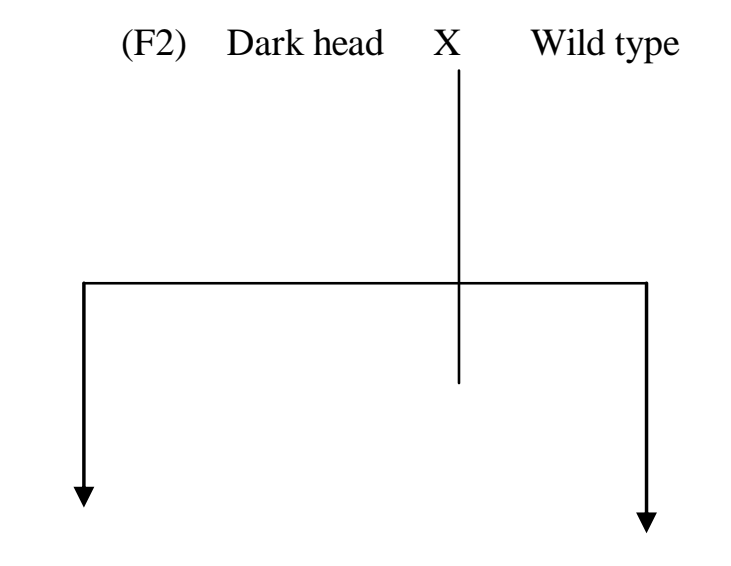

Wild type $(86.1 \%)$
$(13.9 \%)$

Dark head $(13.9 \%)$

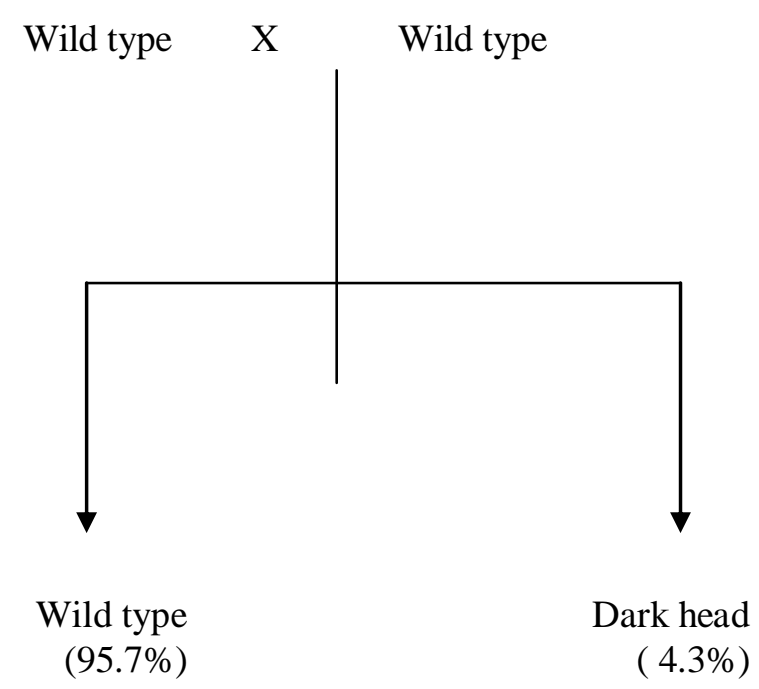

Fig. 4 : Breeding scheme showing reciprocal mass mating between mutants from F2 generation and normal wild type sibs .

Table 1 : Summary of crosses showing that dark head and siphon (dh) is a recessive trait with incomplete penetrance and variable expression

\begin{tabular}{|l|c|c|c|c|c|c|}
\hline \multirow{2}{*}{ Cross } & \multicolumn{2}{|c|}{ Parental Phenotype } & \multirow{2}{*}{ No. of Families } & \multicolumn{2}{|c|}{ Progeny Phenotype } & \multirow{2}{*}{ \% Larval Mortality } \\
\cline { 2 - 3 } & Female & Male & & + & dh & \\
\hline A & dh & $F l\left(\mathrm{dhxdh}^{+}\right)$ & 10 & 441 & 206 & 24.9 \\
\hline B & $\mathrm{Fl}\left(\mathrm{dhxdh}^{+}\right)$ & $\mathrm{dh}^{+}$ & 9 & 222 & 180 & 29.8 \\
\hline C & $\mathrm{dh}$ & $\mathrm{dh}$ & 19 & 37 & 1485 & - \\
\hline D & $\mathrm{Fl}\left(\mathrm{dhxdh}^{+}\right)$ & $\mathrm{Fl}\left(\mathrm{dhxdh}^{+}\right)$ & 12 & 678 & 178 & - \\
\hline E & + & $\mathrm{dh}$ & 12 & 605 & 158 & 14.2 \\
\hline F & dh & + & 3 & 173 & 28 & 15.1 \\
\hline G & F2dh & F2dh & 6 & 23 & 422 & 4.3 \\
\hline H & $\mathrm{F} 2\left(\mathrm{dhxdh}^{+}\right)$ & $\mathrm{dh}$ & 2 & 339 & 141 & 16.8 \\
\hline I & $\left.\mathrm{F} 2(\mathrm{dhxdh})^{+}\right)$ & $\mathrm{F} 2\left(\mathrm{dhxdh}^{+}\right)$ & 6 & 342 & 142 & 26.8 \\
\hline J & $\mathrm{dh}$ & $\mathrm{F} 2\left(\mathrm{dhxdh}^{+}\right)$ & 7 & 446 & 73 & 22.8 \\
\hline K & + & + & 3 & 198 & 9 & 15.2 \\
\hline
\end{tabular}

\section{References}

1. Cheng, M. L. (1972): The inheritance of pigmented-paddle in Culex pipiens . M. S. Thesis, Univ . Calif . Los-Angeles, P.ix-79.

2. Guptavanij , P. and Barr, A. R. (1979) : Plum-eye, a marker for the third linkage group in Culex pipiens (Dipper: Culicidae) . J. Med. Entomol., 16(3) : 219 - 222 .
3. Guptavanij , P. and Barr, A. R., (1982): Two sex-linked mutants, blond (bl) and maroon eye (mar), in Culex pipiens (Diptera : Culicidae) J. Med. Entomol., 19(4) : $394-398$.

4. Vandehey, R. C., (1967): Inheritance of pigmented larval head capsules in Culex pipiens. Mosquito News, 27(1) : $69-73$. 
5. Barr, A. R. , (1975): Culex . P. $374-375$. In: King, R. C., ed. Handbook of genetics, 3. Invertebrates of genetic interest . Plenum Press, New York, p 874

6. Dubash , C. J. , Sakai , R. K. and Baker , R. H. (1982) :Two new body color mutants in the mosquito . J. Heredity, $73: 340-$ 344 .

7. Sharma, V. P., Mani , T. R., Adak, T. and Ansari , M. A. (1977): Colorless eye, a recessive autosomal mutant of Anopheles stephensi . Mosquito News., 37: 667 - 669 .

8. Subbaraw, S. K. and Adak , T. , (1978): Genetic mapping of a larval colour mutant greenish larva with the help of male linked translocations and ruby-eye marker in Culex quinquefasciatus. Mosquito News, 38(1) : $47-51$.

9. Sakai , R. K. , Chaudhry, M. and Baker , R. H. , (1980): An EMS-induced mutant, rose eye in Culex quinquefasciatus . J. Hered ., $71: 136-139$.

10. Shetty , N. J. and Chowdaiah , B. N. , (1976) :Tests for allelism among certain larval color mutants of Culex quinquefasciatus. Mosquito. News. 36(4) : $477-482$.

11. Subbaraw , S. K. and Adak , T. , (1978): Genetic analysis of a larval color mutant, greenish larva, in Anopheles stephensi. Mosquito News., 38(1) : $51-53$.

12. Ouda , N. A. , Al-Chalabi , B. M. and Dikran , B. B. , (1986) : Observation on slow-growth larvae: A new character in the mosquito Culex quinquefasciatus Say (Diptera : Culicidae ). J. Biol . Sci. Res., 17(1) : 211- 217 .

13. Ouda , N. A. and Mehdi , N. S. ,(1988) . Black larvae a recessive lethal mutation in Culex quinquefasciatus Say. J. Biol . Sci. Res., 19(3) : 675- 679 . 


\section{وراثة الرأس السوداء والسيفون فى يرقات بعوضة الكيولكس

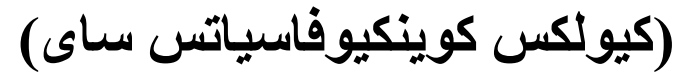

\section{بايعة شلبعى وإبراهيم الغويل}

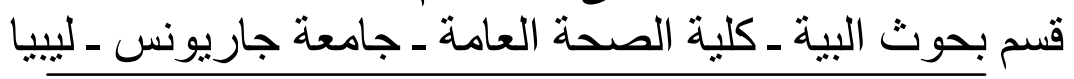

تم وصف طفرة جديدة لنوع البعوض Culex quinquefasciatus , و قد لوحظت

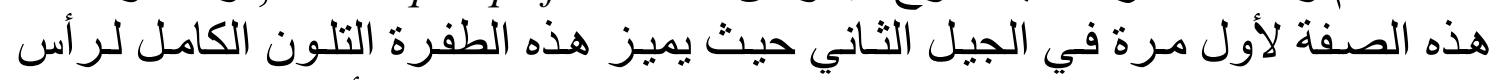

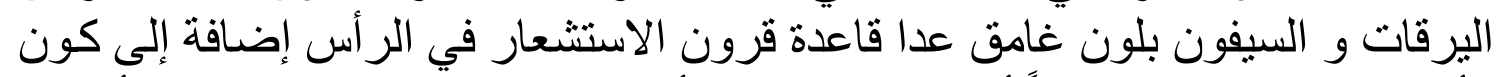

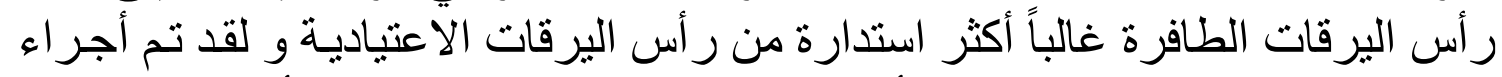

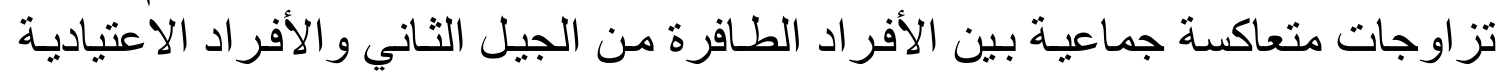

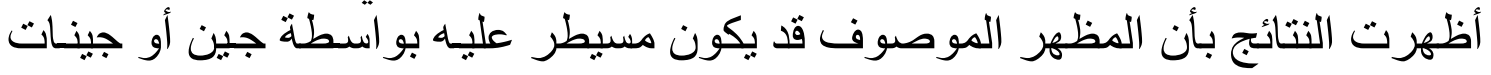

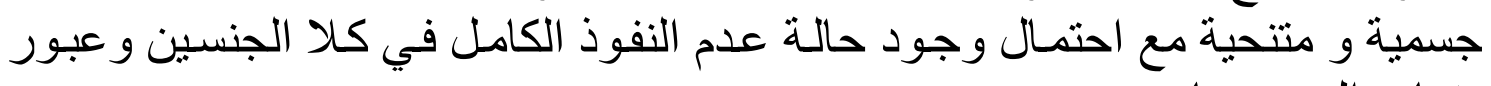
متغاير إلى حد ما. 